\title{
The health care economic-industrial complex: Concepts and general characteristics
}

\author{
Carlos Augusto Grabois Gadelha ${ }^{1^{*}}$, Laís Silveira Costa², \\ José Manuel Santos de Varge Maldonado ${ }^{3}$, Pedro Ribeiro Barbosa ${ }^{4}$, Marco Antônio Vargas $^{5}$ \\ ${ }^{1}$ Science, Technology and Strategic Inputs, Ministry of Health, Brasilia, Brazil; \\ *Corresponding Author: carlos.gadelha@saude.gov.br \\ ${ }^{2}$ Research Group Innovation in Health Care, Oswaldo Cruz Foundation (Fiocruz), Rio de Janeiro, Brazil \\ ${ }^{3}$ Professional Master's Degree Course in Politics and Management of Science, Technology and Innovation in Health Care, Sergio \\ Arouca School of Public Health, Oswaldo Cruz Foundation, Rio de Janeiro, Brazil \\ ${ }^{4}$ Management and Institutional Development, Oswaldo Cruz Foundation (Fiocruz), Rio de Janeiro, Brazil \\ ${ }^{5}$ Department of Economics, Faculty of Economics, Universidade Federal Fluminense, Niterói, Brazil
}

Received 19 July 2013; revised 20 August 2013; accepted 15 September 2013

Copyright (c) 2013 Carlos Augusto Grabois Gadelha et al. This is an open access article distributed under the Creative Commons Attribution License, which permits unrestricted use, distribution, and reproduction in any medium, provided the original work is properly cited.

\begin{abstract}
The strategic role of health care within the Brazilian development agenda has been increasingly recognized and institutionalized. Aside from its importance as a structural element of the Welfare State, health care plays a leading role in generating innovation. Despite this, the productive base of Brazil's health care system is extremely fragile, jeopardizing both the universal provision of health care services and the country's competitive insertion in the globalized environment. This suggests the need for a more systematic analysis of the complex relationships that exist between the technological and the social interests involved in the productive base of health care provision in Brazil. Therefore, the purpose of this article is to enhance our understanding of the productive base of health care, especially given its potential to contribute to a socially inclusive development model, which is the ultimate goal in Brazil.
\end{abstract}

Keywords: Technological Development Policies; Health Care Sector Economics; Health Sciences; Technology and Innovation Management; Policies and Cooperation in Science, Technology and Innovation

\section{INTRODUCTION}

The strategic importance of health care has been widely recognized in Brazil, particularly during the last decade, in various fields of study and activity. It plays an important role in fostering economic growth and national competitiveness as its productive complex, known as the "Health Care Economic-Industrial Complex" (HEIC) ${ }^{1}$, is constituted of a number of important sectors, such as the chemicals and biotechnology industries (pharmaceutical industry, vaccines, blood derivatives and diagnostic reagents); mechanics, electronics and materials (medical equipment and materials); as well as the services sector (hospitals, outpatient clinics etc.). Furthermore, Health Care accounts for $12 \%$ of Brazil's employed workforce, represented by both direct and indirect jobs in industries, hospitals, laboratories, in services offering diagnostics and treatment and in the commercial area.

In Brazil, the national HEIC accounts for 9\% of Gross Domestic Product (GDP), for approximately 25\% of total spending on Research and Development (R \& D) and generates 12 million direct and indirect jobs [3]. From this perspective, it would not be erroneous to state that the economic dimension of health care innovation is largely associated with the dynamism present in economic growth rates, resulting from the high degree of innovation among the productive industries of the com-

\footnotetext{
${ }^{1}$ The conceptualization of the Health Care Industrial Complex (HIC), or Health Care Productive Complex [1,2], is strictly identical to that of the concept of the Health Care Economic-Industrial Complex (HEIC). This newly proposed terminology stems from the fact that the use of the term "HIC" had become largely restricted to industrial segments, attenuating the systemic character of the approach that also incorporates the segment of health care services. In this paper, the terminologies "Health Care Productive Complex", "Health Care Complex", "Productive Complex" and "Complex" will be employed indiscriminately to designate the "Health Care Economic-Industrial Complex" or its acronym "HEIC".
} 
plex.

From this one can conclude that development processses are not just a question of growth, as growth alone does not raise any qualitatively new phenomenon [4]. Similarly, Reference [5] pointed out that the main task of humanity in the twenty-first century would be to establish new priorities for political action in light of a new concept of development, one that would include society as a whole.

In this particular theoretical model, the development pattern must cease to reproduce the consumption patterns of certain minorities and instead seek to meet the basic needs of all people. In health care, this process, more than in any other field, is crucial due to the fact that the analysis of health care priorities presents important challenges that require a systemic view. Such an analysis should consider the institutional model of the health care system, the composition of public and private investment in health care, the demographic and epidemiological changes that have taken place, new technological demands on the provision of services, economic and market dynamics, relations of production and other crucial components that should be analyzed systemically if one is to better understand a given health care system.

With this view in mind, the role of health care within the development agenda has been institutionalized by the Brazilian government in recent years, as can be seen from a series of initiatives that have been implemented in order to integrate industrial policies and health care services. However, despite these efforts, the lack of sufficient coordination between social, economic and innovation policies, as well as the asymmetry of forces that exist in the health care agenda, has jointly ensured that a hierarchical relationship between the interests involved has persisted, thereby jeopardizing the achievement of an inclusive national development pattern.

Growing health care needs, the strategic nature of the industries involved (a door to the future) and the pressure they exert on the balance of payments are clear indicators of the non-trivial challenges that must be overcome when considering the productive and sanitary aspects of health care. All this lends weight to the importance of gaining a deeper understanding of health care's productive base, the dynamics of its subsystems and the diverse interests involved, which is the purpose of this article that, in theoretical and conceptual terms, refers to the Neo-Schumpeterian evolutionist approaches to the HEIC.

The concept of national innovation systems includes all aspects of the economic structure and institutional framework that affect learning processes, and the generation and diffusion of innovation. The concept of the HEIC provides a specific focus of the national innovation systems in health care, which favors the production system of goods and services in this field. The relevance of adopting this concept derives from the fact that this broader perspective is best suited to promoting the development of tools, and helps one analyze public intervention $[6]^{2}$.

From this perspective, this article seeks to contextualize the HEIC and the three subsystems of which it is comprised: the chemical and biotechnology segment, the mechanical, electronic and material segment and the health care services segment, and it presents scenarios, policies and proposals over the medium and long terms for each one. Finally, it summarizes some political-institutional characteristics of the Productive Complex as a whole.

\section{THE HEALTH CARE ECONOMIC-INDUSTRIAL COMPLEX: THE PRODUCTIVE BASE OF THE NATIONAL INNOVATION SYSTEM IN HEALTH CARE}

The Health Care Productive System is particularly complex since it combines the generation and dissemination of technologies, the Welfare State, multi sectorial institutional dynamics, and involves both public and private sectors. The analytical dimension of the HEIC implies a differentiated set of institutional arrangements that include productive sectors and chains, science and technology organizations, enterprises, and regulatory agencies in the areas of health care, intellectual property, and industrial, scientific and technological policies, among others. For this reason, health care is considered as a strategic field within the National Innovation System, stressing the importance of developing adequate policies and investment for this sector.

The HEIC represents an opportunity to overcome the tensions that exist between the economic and the sanitary logics involved in health care and industrial development policies. Despite its complexity, the systemic characteristics of the HEIC define a connection between economic and social logics. In fact, building a universal health care system that is able to meet the population's health care needs, as proposed in Brazil, presupposes the expansion of the national health care productive base. The historical inobservance of this relationship has led to the development of this productive complex without consideration for its systemic characteristics, thus harming the nation's capacity to deliver effective healthcare services and goods, and hindering the effectiveness and competitiveness of the national HEIC to produce suitable social and economic results.

The constitution, in Brazil, of an endogenous innovation base requires the structuring of a network of State

${ }^{2}$ For details see [7-9]. 
institutions that give support to a national strategy, similar to that seen in the areas of energy and agriculture, where Petrobras and Embrapa anchor the innovation process and link it to the private sector. Considering the specificities of health care, the goal for a national expansion of Fiocruz, as expressed in Mais Saúde ${ }^{3}$, should be furthered in order to better face the challenge of constituting a regionalized national innovation network, which would connect this key Science, Technology and Innovation (ST \& I) and health care institution to similar national health care institutions (Instituto Nacional de Câncer, Instituto Nacional de Traumatologia e Ortopedia, Instituto de Cardiologia, among others) and other strategic institutions of innovation in the field of health care. This would be crucial for a long term perspective, which would connect the social and the economic dimensions and which could guide and make an adequate pattern of technological innovation viable, both in the public and the private sectors, thereby allowing for a qualitative leap within an extremely competitive and threatening international environment. Ultimately, it would only be by confronting the challenges posed to innovation in health care and to the reduction in international asymmetries that one could achieve full access to health care for all, irrespective of the technological complexity of the goods and services involved.

The concept of the HEIC emphasizes precisely the relationship between innovation, productive structures and healthcare services, whose interdependence in the evolu- tion of paradigms and technological paths points to the systemic characteristics of this Productive Complex [2]. The set of economic sectors which comprise this Complex are outlined here, based on this concept. Its systemic characteristics become visible through its three subsystems (services; the chemicals and biotechnological industry; the mechanical, electronic and materials industry) and particularly by that of services, since the production of the other sectors necessarily converges on the provision of health care services, making it the key productive force behind the evolution of both the National Innovation System in Health Care (NISH) and the HEIC.

The coordination of services with industrial activities is a central element in the process of the generation and dissemination of innovation that determines the evolution of national productive structures. It is indeed in the services sector that lies the potential to overcome the dichotomies that exist between social and economic dimensions, between the nature of industrial activities and that of services, and between social and innovation policies and those aimed at the development of production.

The intrinsic relationship between the public health care dimension and the productive one is evidenced in Figure 1, which summarizes the concept of the HEIC by expressing the relationship between the services sector and a set of economic-industrial activities. That is, it emphasizes the association of hospital, laboratorial, diagnostic and treatment service provision (services) with that of pharmaceutical, vaccines, blood derivatives and

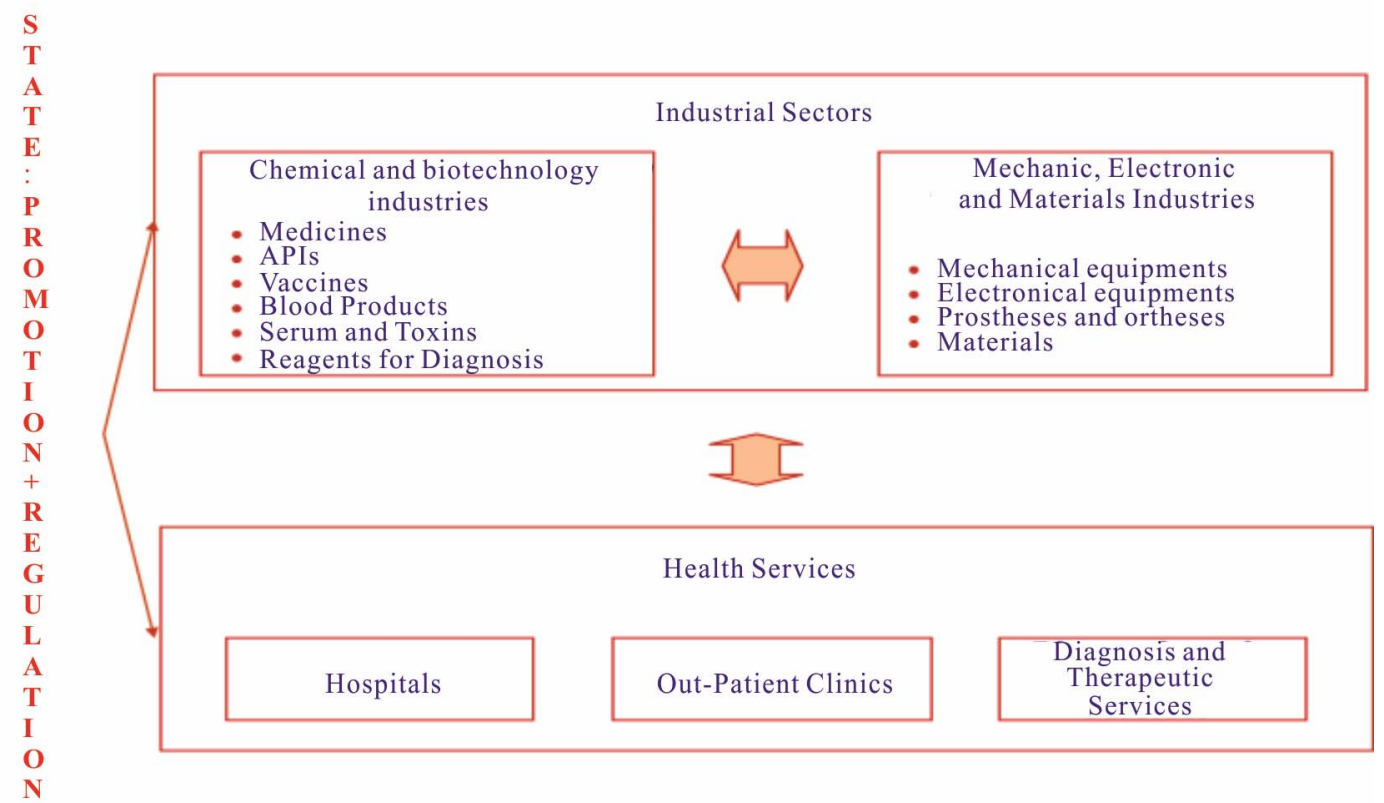

Figure 1. Health care industrial complex morphology. Source: [2].

\footnotetext{
${ }^{3}$ A national program developed by the Ministry of Health and launched in 2007 that stressed, among other priorities, the importance of developing $\mathrm{R}$ \& D in health care.
} 
diagnostic reagents industries (chemical and biotechnological industrial base), as well as that of medical-hospital equipment, medical and dental supplies (mechanical, electronic and materials industrial base).

Thus, in order to analyze the political priorities of the sector, some important challenges are posed which require a systemic approach to health care. One must, for instance, consider the institutional model of the Unified Health System (SUS) ${ }^{4}$, which is universal, as established under the Brazilian Constitution. This characteristic should define, with respect to investment, the optimal combination between the composition of public and private resources: the public should prevail, as in all universal health care systems around the world. In Brazil, this combination is highly inadequate since most of the national Health Care system is, in fact, supported by private resources, which constitutes a major barrier to the consolidation of an effective system of social welfare in the country.

Furthermore, changes in the demographic and epidemiological profile and new technological demands in healthcare must also be taken into account in the planning of HEIC development policies. The main changes that have been observed in the health care area refer to increases in both life expectancy and the complexity of morbidity and mortality profiles, which have increased the incidence of chronic degenerative diseases. Such a scenario puts increased pressure on the industrial and service-providing systems, and requires a greater effort on the part of national policies in order to remove the technological gap between Brazil and the more developed countries. For a better understanding of the challenges and opportunities related to the indispensable advancement of health care knowledge, one should further analyze the characteristics of this productive base, that is, of the three subsystems which form the HEIC.

\section{THE CHEMICALS AND BIOTECHNOLOGICAL BASE SUBSYSTEM}

The development of the chemicals and biotechnological base subsystem directly impacts the capacity to provide universal health care in Brazil, since it accounts for the production of drugs and medicines, vaccines and serum, blood derivatives and diagnostic reagents. This subsystem is characterized by its economic relevance and by the mastering of technologies in strategic areas. Emphasis is given to the need for a systemic approach to productive segments that comprise the HEIC, since the competitiveness of the chemicals and biotechnological subsystem mobilizes areas that are strategic to the advancement of health care, as, for instance, in the case of biotechnology, nanotechnology and fine chemicals. Such characteristics reveal the urgency to adapt policies aimed at the development of this productive base, taking into account the specific characteristics of the Unified Health System (SUS).

The Brazilian pharmaceutical market had a turnover of nearly US\$25.4 billion in 2012 [10]. Developing countries will contribute $31 \%$ to the growth of the global pharmaceutical market in the period 2011 to 2016, including 30\% provided by Pharmerging nations, while Europe (France, Germany, Italy, Spain and United Kingdom) will contribute 13\% and North America 31\% in the same period [11]. It is estimated that the Brazilian pharmaceutical market will show a growth of $12 \%$ to $15 \%$ per year, similar to the estimates for other emerging markets, such as China (15\% to $18 \%$ ) and the Russian Federation (10\% to $13 \%)$. Furthermore, the trade deficit related to the pharmaceuticals market totaled US\$ 5.1 billion in 2012 (Figure 2), representing approximately $65 \%$ of the whole chemical and biotechnological sub-

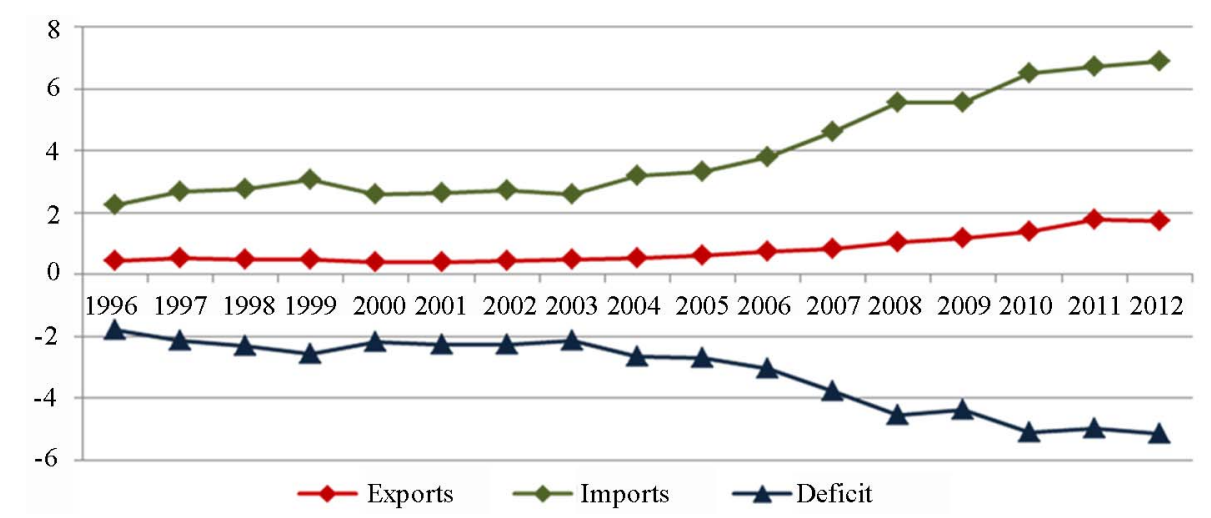

Figure 2. Evolution of the pharmaceutical industry's trade balance (amounts in US\$ billion, adjusted using the North-American Consumer Price Index)—2013. Source: Own elaboration from data provided by [12].

${ }^{4}$ Brazil's Healthcare System (SUS) is a decentralized, regionalized and hierarchized system, mainly characterized for having a policy of universal, complete and non-discriminatory access. 
system trade deficit, of US\$8 billion. Such a deficit, besides indicating a degree of economic vulnerability, points to the nation's fragility regarding health care knowledge, and signals certain particular threats to the management of public health care in this country, for, on the one hand, it unveils the vulnerability of the National Health System and, on the other, it makes it clear that the need to associate the growth in the national productive capacity with active innovation strategies is related to new technological platforms that are based on the advancement of biotechnology, fine chemicals and natural products.

The pharmaceutical industry is characterized by high levels of internationalization and the industrial concentration of large companies in the sector (the ten largest enterprises account for nearly half of the sales of the whole pharmaceuticals market). This reveals significant entry barriers into market economies in view of the high expenditure on R \& D that is characteristic of this sector $[13,14]$. In spite of this characteristic, some niche markets can be identified that allow for the participation of smaller companies, which may represent an opportunity for Brazilian enterprises; this refers to the markets for generic drugs, similar products, pharmochemicals for widespread use, among others. The recent increase in the participation of Brazilian enterprises in the market has essentially been due to the opportunities created by the segment of generic medicines, to strategies of mergers and acquisitions $[15,16]$, and to the intensification of innovative activities [17], although that said, given the restrictions that exist in relation to the size of the players involved, such innovations have been incremental. One should note that the pressures on the pharmaceutical market - a segment that leads the dynamic of the sector in view of the weight of its participation within the subsystem-impose a set of new challenges, suggesting the need to encourage a greater nationalization of this segment, the development of more robust innovation strategies and a consolidation of the production chain.

With respect to political proposals for the pharmaceutical sector, incentives have been suggested for research and innovation in segments related to diseases that have been neglected, and the implementation of transversal initiatives for technological support-elements that are still quite deficient in the national market and contribute to the low levels of innovation experienced in this Industrial segment.

Besides the general characterization of the pharmaceutical industry as a competitive space that determines the dynamics of the chemical and biotechnological subsystem, some particularities of the other segments are worth emphasizing, such as the production of vaccines, blood derivatives and diagnostic reagents. Although these segments sometimes hold their own peculiarities, a clear technological, economic and competitive convergence may be observed, in which the leading pharmaceutical enterprises invade and subject the other segments of the chemical and biotechnological base to their own innovation strategies. This has lead some authors to claim, as in the case of vaccines $[1,18]$, that the distinct segments have become market spaces within a differentiated oligopoly, whose competition is expressed in particular groups of products (therapeutic class, biotechnology segment etc.).

In Brazil, the path to development of the vaccines industry has been marked by the predominant participation of state-owned laboratories, including Bio-Manguinhos/ Fiocruz and Butantan, whose main purpose has been to supply the Brazilian public sector. The most significant entry of the country into the manufacture of healthcare products comprising modern biotechnology has been made possible through the association of an investment program for enhancing the capacity for internal supply and for improving quality with the consolidation of national demand through the National Program of Immunizations (NPI).

In 2012, the government's imports of vaccines for human use totaled US\$585 million, and the State was responsible for more than $95 \%$ of the doses produced, with an expressive evolution of the market [19]. However, in spite of advances in the nation's capacity to produce vaccines and sera, one can still note considerable external dependency, especially regarding the endogenous development of new products and processes. Currently, the main challenge faced refers to the link between production capacity and innovation capacity, by consolidating endogenous $\mathrm{R} \& \mathrm{D}$ activities within the productive environment.

Such a strategy is already on the agenda of major state-owned laboratories (Bio-Manguinhos/Fiocruz and Butantan), as can be seen, for instance, in their current plans for vaccination against pneumococcus, within the scope of the National Program of Immunizations. This program involves the setting up of an R \& D center specialized in vaccines - the result of an agreement between Fiocruz and GlaxoSmithKline-within the context of the political priority for innovation in health care. Nevertheless, a qualitative leap is still necessary in order to maintain a degree of dynamism over the medium and long terms.

The blood derivatives industry, meanwhile, constitutes one of the therapeutic classes of the pharmaceutical industry, developing highly complex activities in the biotechnological field through the processing of human plasma. The main peculiarity of this segment in Brazil refers to the fact that the Brazilian Constitution prohibits the commercialization of blood and its derivatives. On an international level, the production of blood derivatives 
occurs in a limited number of countries, and is concentrated among few manufacturers, thereby following the same pattern as seen in the pharmaceutical industry.

In Brazil, although there is a potential supply of 400,000 liters of plasma per year, the market is strongly dependent on imports. In view of this, the Ministry of Health launched, in 2001, a program aimed at the use of this home-produced plasma, by hiring the services of foreign enterprises for the purpose of plasma processing and fractioning. This strategy, however, led to an explosive growth in the trade deficit of the blood derivatives segment. In 2012, the blood derivate trade deficit represented US $\$ 1.8$ billion, accounting for about $17 \%$ of the total trade balance of the Health Complex [19]. Today, the main initiative aimed at expanding plasma fractioning activities in Brazil is related to the operational launch of Hemobras, the Brazilian Company of Blood Derivatives and Biotechnology. The creation of this enterprise is part of a Brazilian strategy to attain self-sufficiency in the production of blood products, a goal whose major challenge is focused on the coordination of this investment with technological and innovative capacities.

Finally, the industry of in vitro Diagnostic Reagents (DIV) is characterized as a highly concentrated segment, with an annual turnover of nearly US\$25 billion [20]. The growing movement in mergers and acquisitions among enterprises in the segment of reagents, besides being strategic for the competitive re-positioning of these firms, creates barriers to the entry of new enterprises into this market. Brazil is currently the 8th largest market in the world for in vitro diagnostic reagents and has continually attracted multinational companies, thanks to a combination of the expansion of the local market and the rapid growth in public health care expenditure. At present, the 10 largest enterprises in the world in the segment of diagnostic reagents already have either offices or manufacturing plants located in Brazil.

The public sector represents about $60 \%$ of the orders received by manufacturers for diagnostic reagents and the main market strategy of multinational enterprises operating in the country is to offer equipment leasing (commodatum) contracts conditioned to the monthly consumption of a minimal quantity of kits by health care establishments. The latter, with some exceptions, previously used to sign "closed" contracts for equipment leasing (that is, they agreed not to use the kits of other suppliers). This forecasting capacity in connection with the way the acquisition process is conducted combined with the purchasing power of the State, results in more aggressive competition among suppliers in the industry regarding price, quality and technical advice offered. However, in view of expertise they have in distinct segments, some enterprises establish particular niche markets with regard to the demand from the public sector.

\section{Future Prospects}

The One of the factors that underlies both the medium and long term prospects for investments and the development of the chemical and biotechnological subsystem is the dynamic of the world and national pharmaceutical markets, forecast to grow at a rate of $3 \%$ to $6 \%$ in the period 2011 to 2016 [11]. One should not that, according to studies developed by IMS Health, it is estimated that the Brazilian pharmaceutical market will present a growth rate of between $8 \%$ and $11 \%$ per year, lower than the estimates for other emerging markets, such as China (18\% to $21 \%$ ) and the Russian Federation (16\% to $19 \%)$. Another factor exerting influence on this subsystem relates to the expiration of the patents of several drugs commercialized by multinational pharmaceutical companies in the Brazilian market. This reinforces the trend of the increased participation by generics in 2011, which represented about $18 \%$ of the national market [21].

With regard to the new technological trajectories observed in this industry, the strong worldwide movement of mergers and acquisitions among pharmaceutical and biotechnological companies is worth noting. Through this movement, such companies seek to strengthen their productive and financial bases in order to achieve economies of scale and to attain synergies in R \& D investment, ultimately seeking new niche markets and future profitability.

Given this industry's trends, and considering the main policy guidelines for development drawn up over the past 10 years that have emphasized the importance of innovation to such development, as we shall see later, one must strengthen and expand the technological competence of the national pharmaceutical industry, since this industry clearly has weaknesses in its innovative dynamic. In the medium term, and principally in the long term, the expectations are that existing bottlenecks in the productive structure of this subsystem will be overcome, thereby attaining the desired modernization of the industrial park, a competitive equilibrium in the trade balance of this subsector, more employment and income generation, and appropriate contributions to the consolidation of the Brazilian health care system.

Thus, the idea of supporting the formulation of policies for this whole subsystem implies the need to strengthen the base of production and of incremental innovation; giving priority to activities of incremental and radical innovation; constituting a favorable legal framework; adopting innovative boosting mechanisms; encouraging the consolidation of the production chain and the internalization of pharmaceutical production; creating mechanisms for structuring systematic support for innovation within enterprises and strengthening the network of state-owned laboratories, including through 
the setting up of public-private partnerships, thus promoting both an interaction between the different agents within the NISH and the development of this subsystem within Brazil.

\section{THE MECHANICS, ELECTRONICS AND MATERIALS BASE SUBSYSTEM}

The mechanics, electronics and materials base subsystem exerts a special influence on the capacity to provide comprehensive and universal health care. This fact results from the strong association there is between products and medical practices, since they determine which technologies are incorporated into proceedings regarding prevention, diagnosis and treatment of diseases. As a result, this segment illustrates well the relationship between the economic and health care logics, as well as the importance, for the health care sector, of actively and conjointly participating in the formulation of policies aimed at boosting the development of the sector, taking into account SUS guidelines and the socio-sanitary characteristics of the country.

The industries in this segment are characterized as oligopolies based on product differentiation and on the supply of specialized goods, with frequent launches of new treatment and diagnostic options within short technological cycles. This exerts significant pressure on the costs of health care provision. In 2008, the global market of this subsystem was worth US\$ 289 billion, with estimated growth expected to reach US $\$ 487$ billion by the year 2016 [22], and it can be characterized as an extremely concentrated market, on the grounds of several factors such as: The institutional and business environment; the scope of the private market for health care with capacity to absorb the supply; the strong role played by governments in the start-up process and in access to new markets; and the traditional adherence of enterprises to $\mathrm{R}$ \& D [23].

The dynamism of the mechanics, electronics and materials base subsystem is attributed to the incorporation of technological advances, to population ageing and to market growth, emphasizing the systemic connection of this industry to health care policies [24]. In this sense, we must note that the increasing demand for health care, associated with similar growth in the pressure to control public and private sector expenditure, has led this industrial segment to concentrate its efforts on the search for reducing the costs of treatment.

In Brazil, this industry was first structured when the development plan that promoted import substitution was in force, in the period between the 1950s and the 1980s. With the advent of commercial liberalization, there was a slowdown and a decrease in the participation of this national segment. In the second half of the 1990s, the lack of competitiveness of national health care industry was further evidenced when the market expanded after the creation of the Real Plan as the weight of public demand increased, in result of the SUS' implementation.

The importance of this segment is worth emphasizing within the broader conceptualization of development, since it accounted for 103,840 direct and indirect jobs in 2009 alone. Furthermore, this industrial segment had a total turnover of US\$4.42 billion in 2009. It is also worth noting that the most dynamic segments refer to medicalhospital, implant and dental equipment, which represent $40 \%$ of national production [25]. Nevertheless, this industrial segment still suffers from a low level of international competitiveness, which is clearly evidenced in the recent evolution of its trade balance, as shown in Figure 3 , pointing to a resulting deficit of US\$ 2.5 billion in 2012.

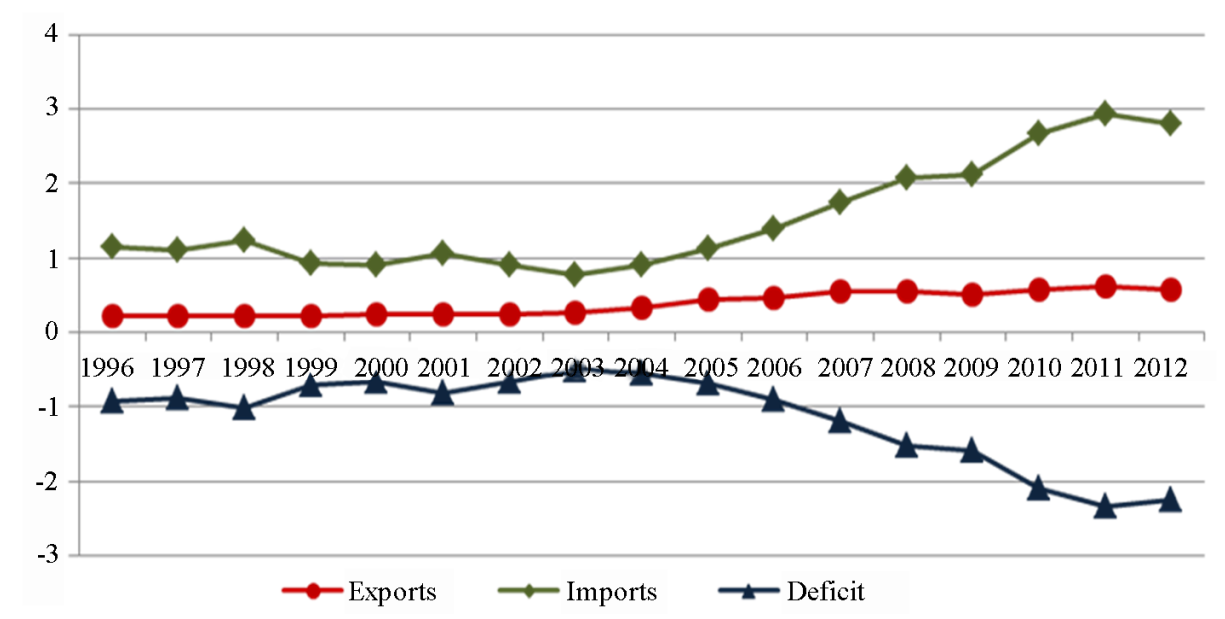

Figure 3. Evolution of the mechanics, electronics and materials industry's trade balance (amounts in US\$ billion, adjusted using the North-American Consumer Price Index)—2013. Source: Own elaboration from data provided by [12]. 


\section{Future Prospects}

The development of this production segment over the medium term, in Brazil, presents some positive indicators. These include a political-institutional convergence, based on the adoption of both the HEIC systemic approach and the political agenda of the pharmaceutical segment by the Industrial Policy of Foreign Commerce, and the priority that has been given to the initiative within the scope of the program "Mais Saude" as well as in the Policy for Productive Development; through the PAC of Innovation, coordinated by the Ministry of Science and Technology; and through the launch of Profarma 2, by the national development bank (BNDES) ${ }^{5}$.

Furthermore, an expansion in direct foreign investment and in mergers and acquisitions, and the increasing use of information and communication technology have been duly noted, boosted by new guidelines for cost reductions, greater agility in service provision and better quality, which suggests the need for more coordination between HEIC subsystems. To this, one should add the major advantage multinational companies have in entering the Brazilian market for manufactured products without there being any domestic products to compete, which refers not only to imports substitution but also to the consolidation of the technological profile and of the productive capacity of domestic industry.

In the long term, some elements in the health care field suggest an influence on the behavior of the medical-hospital materials and equipment industry. Among these, the following are especially noteworthy: the pressure to reduce costs (an ageing population and the expansion of health care services); preventive healthcare; telemedicine (with a particularly relevant impact given Brazil's regional characteristics, and especially those of infrastructure in health care units); home healthcare; and new technologies and the benefits associated with them.

These characteristics enable one to build long-term sectorial policies that should include: use of the State's purchasing power; financing and other incentives for mergers and acquisitions and professionalization of the management of national enterprises; financing for investment in equipment and materials for the SUS; promoting exports (enhancement of the competitive advantages of national enterprises); incentives for the development of infrastructure of technological services for the qualification of suppliers - this can especially lead to improvements in production, inventory and distribution

\footnotetext{
${ }^{5} \mathrm{PAC}$ is an acronym for "growth acceleration program", a highly prioritized program of the Brazilian federal government aimed at defining priorities for developing the country's infrastructure in order to foster national development. Other sectors have also defined strategic areas and specific plans, such as the Health care sector, with its Mais Saúde program, and the S \& T sector, with its PAC for Innovation. By the same token, Profarma refers to an important investment program for strengthening and developing national HEIC in Brazil.
}

processes; incentives for the development of innovation clusters and for the full use of political and sectorial forums; creation of a regulatory environment that connects quality, innovation and the pressure to reduce costs with national industries' vulnerabilities, and finally, incentives for the constitution of networks involving enterprises, universities and technological institutes. In this sense, the agreement signed in 2009 between Fiocruz and the Government of Ceará State for the construction of the first Brazilian Technological Pole, which will specialize in the Health Economic-Industrial Complex, is worth mentioning.

\section{THE HEALTH CARE SUBSYSTEM}

This is the subsystem with the greatest economic weighting within the whole system, whether because of its intrinsic relationship with employment and income generation, or because it constitutes the end market for the products of the other segments of the production complex, thus disclosing the systemic characteristics of the health care productive base (HEIC). The health care subsystem is structured according to health care systems whose organization is determined by epidemiological and demographic aspects. Health care services reveal important vectors that determine the system's structure and performance, with a clear interconnection between political, institutional, social and economic elements. It determines the directions of the national trajectories of innovation as well as the global dynamics of investments -issues that once again emphasize the intrinsic relationship between health care and development.

Health care systems are coordinated in accordance with diverse principles, where the levels of technological complexity and the economic scale stand out. The segment of hospitals and that of complex diagnostics and therapy centers are those which best illustrate the economic dynamism of services, since they are concomitantly specialized producers and consumers of differentiated technologies and innovation. In observing the current trends of national and international markets, one can perceive a gradual reduction in the role of hospitals in this segment that becomes increasingly diversified as a result of the configuration of health care integrated networks, at the heart of which primary healthcare acquires growing importance (Figure 4). The health care integrated system is configured by means of the incorporation of new technologies, internal reorganization of space, new forms of healthcare provision, as well as the search for new managerial tools and structures. Scientific and technological advances, previously only observed in hospitals, are now gradually being transferred to other environments, leading to innovations such as day-care hospitals, out-patient clinics, home care, nursing centers [26], among others. 


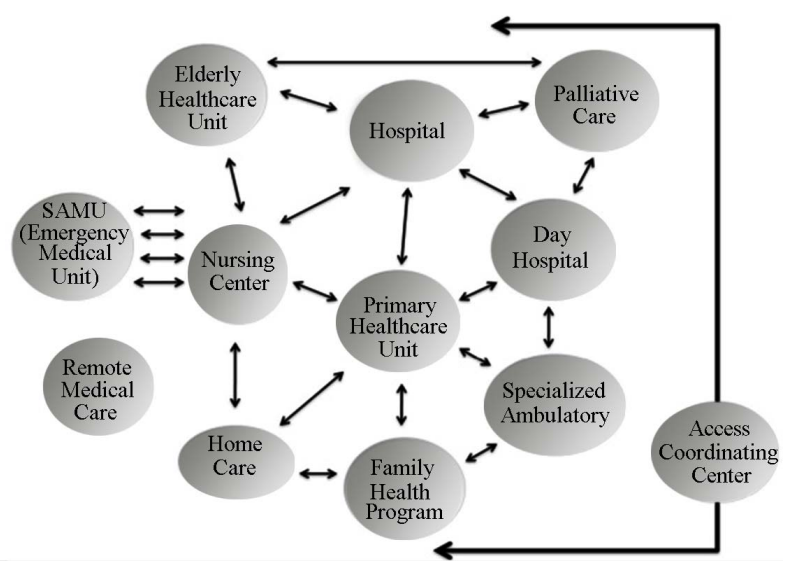

Figure 4. Systems with a greater differentiation in services: configuration of integrated networks of health care services. Source: Adpated from [27]. N.B.: Ambulatory equals specialized out-patient clinic.

Aside from the significant technological changes observed in the health care model, the importance of the priority of policies aimed at the development of the whole HEIC becomes evident when demographic and epidemiological determinants are considered. These emphasize the transformations in the profile of demand that have taken place, with the population ageing and the burden of chronic diseases increasing.

Based on the assumption of universal health care, and considering the growing pressure for greater control over health care expenditure, the need to search for more efficient technologies for health care provision, with adequate cost-benefit ratios becomes all the more evident. It is worth noting that these political determinants reveal the strong incoherence that exists in the public sector financing of the SUS, whose participation does not reach $50 \%$ of total health care expenditure [28], as shown in Table 1.

Hence, the socio-political constitutional pact that establishes a universal system cohabitates with the expenditure structure of a mercantile health care system, whose proportion of the private sector's spending is incompatible with the notion of universal access. Data from the National Agency of Supplementary Health (ANS) shows that demand for supplementary health care has increased significantly, to a total of 48.7 million beneficiaries as at the end of 2011 [29]. In a broader sense, the expansion of supplementary health care has been characterized by a wish to guarantee greater consumer rights, by extending the list of items covered (periodically updated), improving the quality requirements for health care provision, ensuring the economic sustainability of enterprises in the sector, meeting contract responsibilities, and by implementing other measures of considerable impact on the middle class, such as allowing for the portability of Health Care Insurance.
The big issue this area faces is with regards to the limits in its growth which, in principle, could represent a negative factor for the constitution of a universal system in the country, since its focus is not only on the poor and excluded This is to say, the private sector currently serves $32 \%$ of the Brazilian population and should not be disregarded by governmental planning and programming of the health care network. This, however, has not been the norm, as shown by the constant difficulties experienced in implementing mechanisms for repaying the SUS in proceedings of greater complexity. From this perspective, the strengthening of the SUS and the gradual inclusion of the middle class appear to be urgent structural requisites for configuring the SUS as a quality universal system, involving distinct economic strata, even more so within the context, recently much disseminated, of the expansion of the middle classes as a result of social improvements observed over the last decade. Otherwise, there is a risk of the SUS, defined by the Brazilian Constitution as a universal system, undergoing a reversal, and becoming a focused system, low in quality and unattractive to society.

Not only has a financing base, compatible with the commitment of constituting a universal system in Brazil, not been created, but there are still persistent gaps in healthcare provision in some regions and within metropolitan areas. That is, universal access still presents significant limitations in quantitative, qualitative, regional and local terms. The extinction of the CPMF (a temporary tax on financial transactions, created with the purpose of increasing the funding base of the public health care system), the failure to enact complementary legislation to Constitutional Amendment No. 29 (the EC29, clearly defining mandatory expenditure on health care) and the failure to approve alternative mechanisms for funding the SUS (such as a Social Health Care Tax) clearly show the lack of political support for the actual constitution of a universal system in Brazil. The fact that the issue of how to fund the SUS has been debated predominantly within the health care sector sphere suggests that the sustainability of a universal system has not yet become a matter of sufficient importance within the sphere of the executive and legislative powers.

Moreover, there has been a progressive decrease in the participation of federal funding, without, however there being any sign of the necessary improvements in municipal management mechanisms, and without there being any evidence of the satisfactory performance of the states in the organization of a regionalized system.

Consequently, federal spending remained practically unchanged in relation to GDP (being 1.7\% of GDP, in 2007). In view of the decentralizing logic that guides the SUS's operations, $70 \%$ of total federal spending is transferred to States, the Federal District and Municipalities. 
Adding in the funds provided by the States and Municipalities themselves, public expenditure on health care reached a total of 3.6\% of GDP. The proportion of Government Spending in relation to GDP and in relation to Total Government Spending is incompatible with any universal system. Table 2 shows that even when considering Organization for Economic Co-operation and Development (OECD) countries (which comprise non universal systems such as that of the United States), there is a huge disparity. In developed countries, public spending represents more than $70 \%$ of total spending on health care. There is no single universal system anywhere in the world whose public sector financing falls below this threshold. In Brazil, meanwhile, a society with marked social inequality and with $68 \%$ of its population dependent on the SUS, the public sector's participation is below $50 \%$ and, in addition, health care accounts for a small proportion of total government spending in comparison to other OECD countries (Table 2). It is abundantly clear then that, irrespective of serious managerial issues, this financing is incompatible with the prime goal of providing the country with an equitable, comprehensive and universal health care system.

Aside from these relevant financing issues, one should note the challenges faced by the SUS when considering the national trend towards the integration of the health care system, which include the need for a better management of the resources that are available within the system and the need to shift the system's patient entry point from hospitals to less technology driven service providers, such as primary health care (PHC) providers. Despite this, in Brazil the hospitals continue to occupy a central role in the provision of health care services, accounting for nearly half of total national health care spending [30], and a relevant proportion of the population still enters the system through the hospitals. One should note that in the period between 1976 and 2005, there was a significant increase in the number of hospitals (35\%), to 7,155 establishments, and yet there was a reduction in the number of hospital beds [31].

With respect to the hospital segment, two trends have been consolidated: medium and large sized hospitals, with better conditions of economic sustainability and having greater technological density; and small hospitals, tending to specialize in more efficient and more effective extra-hospital services. The dynamics of the hospital segment in Brazil presents, however, a great challenge to industrial policy with respect to hospital health care. The decrease in the number of beds was not accompanied by a technological increment of hospitals that one would expect in view of the adoption of the integrated health care system, which presupposes an increased complexity in hospital care and, thus, greater technological density. In short, when looking at the inventory of hospitals in Brazil, one can observe that the country is following neither the international trend, nor its own epidemiological demands.

\section{Future Prospects}

In order to analyze the prospects for the health care service subsystem in the medium term, the goals established under the program "Mais Saúde" are taken into account, suggesting expectations of an increase in public

Table 1. Composition of final consumption in the health care area by institutional sector as a \% of GDP—2003 to 2009.

\begin{tabular}{|c|c|c|c|c|c|c|c|}
\hline Institutional sectors/products & 2003 & 2004 & 2005 & 2006 & 2007 & 2008 & 2009 \\
\hline Households & 4.8 & 4.8 & 4.8 & 4.9 & 4.8 & 4.7 & 4.8 \\
\hline Public Administration & 3.2 & 3.2 & 3.3 & 3.5 & 3.5 & 3.5 & 3.8 \\
\hline Not for profit institutions providing services to households & 0.1 & 0.1 & 0.1 & 0.1 & 0.1 & 0.1 & 0.1 \\
\hline Total & 8.1 & 8.1 & 8.2 & 8.5 & 8.4 & 8.3 & 8.7 \\
\hline
\end{tabular}

Source: [3].

Table 2. Public spending on health care as a \% of total health care spending and of government spending—Brazil 2003-2008.

\begin{tabular}{|c|c|c|c|c|c|c|}
\hline \multicolumn{7}{|c|}{ Public Expenditure on Health Care as a \% of Total Health Care Expenditure } \\
\hline & 2003 & 2004 & 2005 & 2006 & 2007 & 2008 \\
\hline OECD Average & 71.9 & 71.8 & 72.0 & 72.7 & 72.7 & 73.1 \\
\hline Brazil & 41.3 & 43.3 & 40.1 & 41.7 & 41.6 & 44.0 \\
\hline \multicolumn{7}{|c|}{ Public Expenditure on Health Care as a \% of Total Government Expenditure } \\
\hline & 2003 & 2004 & 2005 & 2006 & 2007 & 2008 \\
\hline OECD Average & 14.8 & 15.1 & 15.3 & 15.5 & 15.7 & 15.7 \\
\hline Brazil & 4.4 & 5.1 & 4.7 & 5.1 & 5.4 & 6.0 \\
\hline
\end{tabular}

Source: Own elaboration from data provided by [30]. 
spending proportionally higher than the growth in GDP. It is worth emphasizing that the rise in the share of public financing is a sine qua non condition for the effective consolidation of the public and universal system. Furthermore, we emphasize the need for State mechanisms to decommoditize services concomitantly with the current supply of services on a mercantile base.

In the long term, considering the institutional health care agenda, there is a perspective for spending on health care to grow, reaching $11 \%$ of GDP with the rise in the public sector's participation, inverting the current distribution between public and private sector spending with a predominance in the participation of the latter. The perspective is for the government to become accountable for $70 \%$ of health care expenditure, thus reaching the level of developed countries and consolidating an effective system of social protection. The rise in the share of the federal government within the composition of health care expenditure presupposes complementary legislation to Constitutional Amendment No. 29.

As for policies, the SUS requires new mechanisms for coordination and regulation in order to adequately implement the regionalization of health care systems based on the logic of sustainable arrangements, considering the necessary rationalization and integration of roles of the several governmental spheres. For this to happen, a considerable degree of resolving capacity and the intensification of the basis of information technology (IT) are prerequisites. Such an intensive process of innovation reveals once more the systemic character of the HEIC, for requiring effective policies regarding the incorporation of technology, which is determined by the improved regulatory capacity of the State and by certain technological options made on proven cost-benefit bases.

In the sphere of public sector investment, some potential strategies are highlighted, such as the establishment of public-private partnerships, the need to reflect on the limitations of existing models and the demand for better qualified Brazilian public sector management. Finally, the strengthening of the State's role as a formulator and promoter of programs for health care provision and innovation presupposes their technical and political strengthening, as well as the use of the State's purchas- ing power.

\section{POLICIES FOR THE DEVELOPMENT OF THE HEIC-AN ANALYTICAL SYNTHESIS}

Recent studies demonstrate the relative weighting of the health care sector within the economy. Activities related to health care accounted for about $9 \%$ of final consumption in the Brazilian economy in 2009 [3]. One should stress the segment of health care services that, associated to those of the chemical and biotechnological base, and those of the mechanics, electronics and materials base, show a vector of limitless innovation for the HEIC.

The consumption of health care reveals the relevance of the role of the State in this system, when one considers the institutional model applied to the health care system in Brazil. Being an important provider, a relevant consumer and responsible for almost $50 \%$ of its resources, in addition to having a regulatory role, between them suggest the protagonism of the public sector, including a role where it can put forward policies for the HEIC's development. Thus, a virtuous cycle could be fostered involving public spending, investment, innovation, and the expansion of income and employment. Furthermore, with respect to the level of employment, around $10 \%$ of Brazil's qualified workforce works in the field of health care [32].

While the data indicates a clear connection between health care and development, the national industrial base's innovation capacity is still not sufficient to ensure the full development of the HEIC, given the low participation of enterprises in productive activities and high technology, as shown in Table 3 [33]. As a result, both the competitiveness of the productive system and the national health care policy, from a broader perspective of universal social protection, are in a situation of extreme vulnerability.

Moreover, the evolution of the national HEIC trade balance, shown in Figure 5, clearly illustrates this conjuncture (deficit of US\$10.2 billion in 2012) and highlights the fragility of the national productive and techno-

Table 3. Structure of innovative activities of industries in the complex (Brazil): the low level of investment by firms in innovation.

\begin{tabular}{|c|c|c|c|c|c|c|c|c|}
\hline \multirow[b]{3}{*}{ Year } & \multirow[b]{3}{*}{$\begin{array}{l}2001 \\
2003\end{array}$} & \multirow{2}{*}{\multicolumn{2}{|c|}{$\begin{array}{c}\text { Innovative firms (\%) } \\
\text { Innovation Rate }\end{array}$}} & \multicolumn{4}{|c|}{ Share of the turnover } & \\
\hline & & & & \multicolumn{2}{|c|}{ Innovation Activity } & \multicolumn{2}{|c|}{ Internal R\&D } & \multirow[b]{2}{*}{2008} \\
\hline & & $\begin{array}{l}2003 \\
2005\end{array}$ & $\begin{array}{l}2006 \\
2008\end{array}$ & 2003 & 2005 & 2003 & 2005 & \\
\hline Pharmaceutical & 50.4 & 52.4 & 63.7 & 3.4 & 4.2 & 0.5 & 0.7 & 1.4 \\
\hline Equipment/Materials & 45.4 & 68 & $*$ & 3.1 & 5.3 & 1.2 & 2.3 & $*$ \\
\hline
\end{tabular}

Source: Own elaboration from [33] database. 


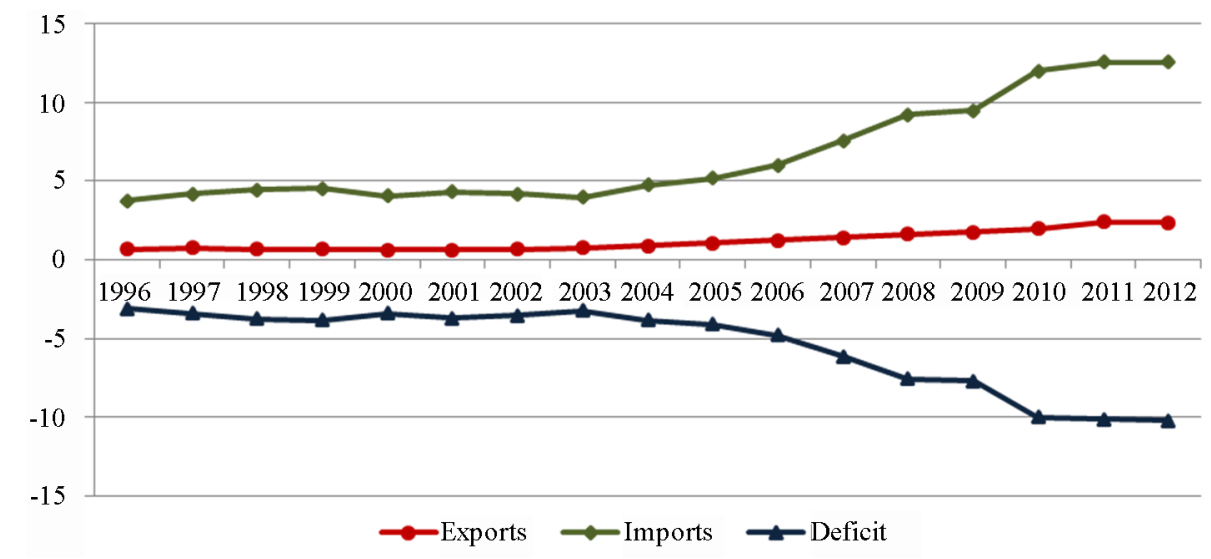

Figure 5. Evolution of the Health Care Economic-Industrial Complex's trade balance (amounts in US\$ billion, adjusted using the North-American Consumer Price Index)-2013. Source: Own elaboration from data provided by [12].

logical capacity. Figure 6, meanwhile points to specific areas where Brazilian vulnerability is at its highest in showing the composition of the HEIC's imports, exports and its trade balance.

It is pertinent to point out that this deficit shows, among other things, that the level of expenditure on R \& $\mathrm{D}$ is insufficient when compared to the needs and robustness of the national health care sector. One should note that Brazil is the eightieth largest pharmaceutical market and the eleventh largest market for medical equipment in the world. Despite this, and thanks to a history of consistently inappropriate and sometimes even non-existent industrial policies, a lack of a systemic approach to the development of the HEIC, regulatory and financial ineffectiveness and insufficient levels of R \& D expenditure, the deficit in the HEIC trade balance was a sizable US\$10.2 billion in 2012 [19].

Analyzing this result from the perspective of certain regional blocks and selected countries, one can see that the majority of Brazil's HEIC deficit comes from trade relations with the European Union, although the recent development of trade relations between Brazil and developing countries like China, India and Russia might require further attention. In the period from 1996 to 2012 the trade relations mentioned above increased fourfold, indicating the fragility of CEIS competitive industries, even when comparing to emerging countries themselves. One should note that the strategic nature of this complex was only recently recognized within the scope of leading national development policies, which could account for an as yet weak set of results in the outcomes of the new priorities set for the HEIC's development.

One should, however take note of the efforts made by the Brazilian government over the past decade to try to improve the national system of innovation in health care, and try to reverse this adverse situation. From among the main government initiatives one should mention the launch, in 2003, of the Industrial, Technological and Trade Policy [34], by the Ministry of Development, Industry and Foreign Trade, which prioritized two issues on the agenda of the extreme centrality of macro politics: a defense of the need for an industrial policy and the selection of some strategic sectors to foster national development, including, drugs and medicines [34].

In 2004, the National Policy for Science, Technology and Innovation in Health Care (PNCTIS) was launched during the 2nd National Conference on Science, Technology and Innovation in Health Care. This program represented an important milestone in the advancement of S\&T in health care in Brazil in that it established health care research as a crucial tool to improve the general health of the population [35].

By the same token, emphasis on health care as a right of all citizens, and the importance of the HEIC within this context, was reaffirmed by the "Mais Saúde" Program, launched by the Ministry of Health in 2007, which defined the Health Care Industrial Complex as one of the main strategic priorities for health care policy [32]. It recognized the need for improvement in the innovative and productive structure in order to increase competetiveness so as to be able to face international competition on an even footing. Thus, for the first time, the importance of the HEIC was officially incorporated into the social policy agenda in Brazil.

In addition, health care was recognized as strategic to national development and identified as one of the areas that invests most in research and development in Brazil. Health care was therefore singled out as a strategic area within the PAC for Innovation of the Ministry of Science and Technology, in 2007 [35].

With the HEIC now included on its list of six main strategic areas (areas with doors to the future because of their intensive use of science and technology), the Productive Development Policy (PDP) was launched in 

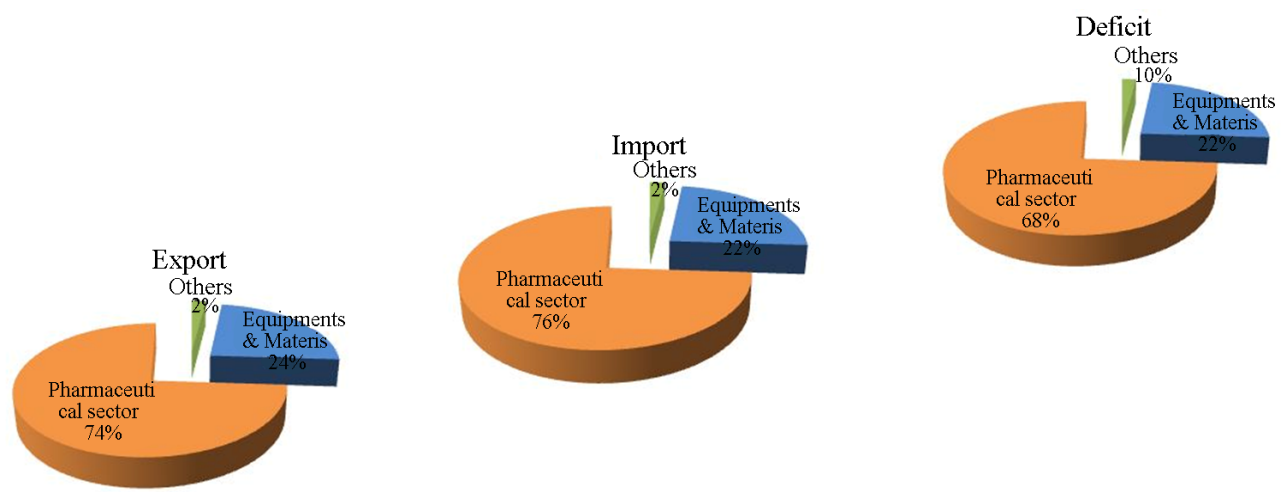

Figure 6. Participation of the productive sectors in exports, imports and the HEIC trade balance in 2012. Source: Own elaboration from data provided by [12].

2008, emphasizing the need to improve national capacity and competitiveness [36].

Among more recent initiatives with an impact on health care, we have the "Brasil Maior", released in 2011 by the Presidency of the Republic of Brazil, and the "National Strategy for Science, Technology and Innovation 2012-2015" (ENCTI), implemented by the Ministry of Science, Technology and Innovation, in 2012.

The Brasil Maior Program offers a new understanding of industrial, technology, services and trade policy aimed at stimulating innovation and domestic production to boost industrial competitiveness, generating employment and income. Among its planned measures, it should be noted that the Government Procurement Law stipulates that a margin of preference of up to $25 \%$ can be established in the bidding process for manufactured products and services that meet the Brazilian technical objectives for national development [37]. These margins cover drugs (medicines) and biological products manufactured in Brazil as well as health care equipment, and are defined taking into account the generation of employment, income, innovation and technological development within the country.

The ENCTI, in turn, reaffirms the priority of the drug (medicines) segment and production complex, pointing out a number of shortcomings in the innovative national productive base that must be overcome, as well as emphasizing the need to promote mechanisms to stimulate innovation in health care and intensify the transfer of technology to the national public sector laboratories [38]. Through the ENCTI, the State has once again assumed its role in facing the challenges of redefining and boosting the development of health care's productive basis through the coordination of the multiple aspects involved.

One should also consider, especially from the point of view of the Health Care Economic-Industrial Complex, efforts made to establish partnerships between government-run laboratories and private domestic producers of active pharmaceutical ingredients under the so-called Productive Partnerships for Development-PDPs program.

This initiative, introduced by the Ministry of Health in 2009, as well as the Brasil Maior Program of 2011, between them consolidate the strategic role played in Brazil by the development of the industrial park to improve the supply of health care and access to essential medicines to the population, to strengthen national laboratories and companies, to reduce Brazil's dependency on imports and hence help reduce the trade deficit. Partnerships between public and private entities in health care can help defend the public interests by achieving economic growth and developing a national productive sector that is able to produce according to Brazilian epidemiological needs [15].

Since 2006, the Ministry of Health has initiated a centralized purchasing process with the aim of centralizing the acquisition of the total national demand for these products, promoting price reductions through negotiations that take into account the high volume of purchases. This centralized purchasing of strategic and high cost medicines by the Ministry of Health is the basis for the effectiveness of the partnerships in question, given the economies that can be achieved through public sector buying. Thus, PDPs have a clear and exclusionary requirement for approval which is that the prices offered to start a new partnership should be lower than those prior to its establishment. These prices should also be gradually reduced over the life of the partnership.

One should also note the potential of the Brazilian State to use its industrial equipment and materials purchasing power, to name another example of its potential influence on the industrial segment. In this case its direct and indirect purchases represent a demand close to $50 \%$ of total sales by industry [39]. Thus the State, in its role as a major consumer of goods and services from the health care industries, can direct their development through preferential purchasing. 
Public procurement, therefore, ensures that prices are driven by demand and not by supply. Through it, the State can also use this artifact to stimulate economic activity and employment, strengthen domestic firms, increase its competitiveness throughout the country, as well as reduce regional discrepancies [40], remembering that public procurement should ultimately target investment in physical infrastructure, strengthen human capacities and contribute to the country's overall development [41].

In this context, procurement and contracting are not solely limited to the function of obtaining services, materials and equipment for the running of government in accordance with the law. This conclusion has been a recurring theme in a number of studies investigating the articulation and promotion of public purchasing innovation, and the theme of seminal studies that were conducted in the 1970s and 1980s involving public procurement and innovation [42], which classified public sector purchasing as a strong element in the consolidation of companies (especially small businesses).

Reinforcing this perspective, one should stress in its defense that the use of the State's purchasing power lies in its potential to control demand in order to achieve its goals related to national development. By signaling the public sector's needs, the State can stimulate the devel opment of innovative solutions to fulfill society's newdemand profile [28].

\section{FINAL CONSIDERATIONS}

This article has discussed the Health Care EconomicIndustrial Complex (HEIC) in Brazil, and its role within the national development agenda. It has outlined the complexity of this analysis, and the variety of relationships involved in the provision of health care in this country, stressing the balance that has to be struck between the economic interests of its knowledge and productive base and the growing social needs of the population.

In considering the importance of achieving a proper welfare state as defined in the federal Brazilian Constitution of 1988, fulfilling the principles of the SUS in terms of providing a universal, complete and non-discriminatory public health care service, and obtaining a competitive insertion into the global market-place, the article has stressed the importance of policies aimed at the development of the HEIC, both in the short and medium terms. The outlook for health care in the medium and long terms is to overcome the bottlenecks and dichotomies that exist between its economic and its social logic-a matter of extreme importance for the consolidation of the national health care system in Brazil.

In order to achieve this objective, policies aimed at fostering the HEIC's development in Brazil pose a special challenge in terms of the need to promote coordi- nated policies, still very much lacking in most sectors, which can have a positive effect on both the provision of health care and on the overall performance of national economic and social development.

It should be noted that the systematic interaction between health care policies, services and industries, is an issue that relates to access to social justice, as guaranteed by the Constitution of 1988, which should strengthen the recognition of the strategic characteristics of the HEIC. Data show that there is still much to do in order to increase investment in health care and overturn the weaknesses of its productive base. This requires, in essence, a deep transformation and an adaptation in the system of promotion and regulation of health care innovation and policy, as well as an effective coordination between industry, science and technology, which is both economically competitive and socially inclusive.

\section{REFERENCES}

[1] Gadelha, C.A.G. (2002) Estudo da competitividade de cadeias integradas no Brasil: Impactos das zonas livres de comércio (Cadeia: Complexo da Saúde). Campinas: IE/ Neit/Unicamp/MCT-Finep/MDIC, Nota Técnica Final.

[2] Gadelha, C.A.G. (2003) O complexo industrial da saúde e a necessidade de um enfoque dinâmico na economia da saúde. Ciência e Saúde Coletiva, 8, 521-535. http://dx.doi.org/10.1590/S1413-81232003000200015

[3] IBGE (2012) Instituto Brasileiro de Geografia e Estatística. Conta satélite da saúde. Diretoria de pesquisas, coordenação de contas nacionais, Sistema de contas nacionais 2007-2009.

[4] Schumpeter, J.A. (1985) Teoria do desenvolvimento econômico. 2nd Edition, Nova Cultural, São Paulo.

[5] Furtado, C. (1998) O Capitalismo Global. Paz e Terra, Rio de Janeiro.

[6] Costa, L.S., Gadelha, C.A.G. and Maldonado, J. (2012) A perspectiva territorial da inovação em saúde: A necessidade de um novo enfoque. Revista Saúde Pública, 46, 59-67.

[7] Mytelka, L. (1993) A role for innovation networking in the other two-thirds. Futures, 85, 694-712. http://dx.doi.org/10.1016/0016-3287(93)90108-6

[8] Lastres, H.M.M., Cassiolato, J.E. and Arroio, A. (2005) Conhecimento, sistemas de inovação e desenvolvimento. Editora da UFRJ e Contraponto, Rio de Janeiro.

[9] Lastres, H.M.M., Cassiolato, J.E. and Maciel, M.L. (2003) Pequena empresa: Cooperação e desenvolvimento local Relume Dumará Editora, Rio de Janeiro.

[10] Abifina (2013) Estatísticas. http://www.sindusfarmacomunica.org.br/indicadores-econ omicos/

[11] IMS Health (2012) The global use of medicines: Outlook through 2016.

http://www.imshealth.com/deployedfiles/ims/Global/Cont ent/Insights/IMS\%20Institute\%20for\%20Healthcare\%20I 
nformatics/Global\%20Use\%20of\%20Meds\%202011/Medicines Outlook Through 2016 Report.pdf

[12] SECEX/MDIC (2013) AliceWeb.

http://aliceweb.desenvolvimento.gov.br/

[13] IMS Health (2008) Top-Line market data. http://www.imshealth.com

[14] Febrafarma (2008) Federação Brasileira da Indústria Farmacêutica. http://www.febrafarma.org.br

[15] Barbosa, A., Mendes, R. and Sennes, R. (2007) Avaliação da política industrial, tecnológica e de comércio exterior para o setor farmacêutico. Estudos Febrafarma, São Paulo.

[16] Gadelha, C.A.G., Maldonado, J. and Vargas, M.A. (2008) Estudo setorial sobre a indústria farmacêutica. Nota Técnica projeto "Uma Agenda de Competitividade para a Indústria Paulista”, Instituto de Pesquisas Tecnológicas do Estado de São Paulo-IPT, São Paulo.

[17] Capanema, L.X.L. (2006) A indústria farmacêutica brasileira e a atuação do BNDES. BNDES Setorial, Rio de Janeiro.

[18] Temporão, J.G. (2002) O complexo industrial da saúde: Público e privado na produção e consumo de vacinas no Brasil. Editora Fiocruz, Rio de Janeiro.

[19] GIS (2012) Grupo de Pesquisa de Inovação em Saúde (ENSP/FIOCRUZ). Sistema de acompanhamento e análise do Complexo Econômico-Industrial da Saúde.

[20] Paiva, L. (2009) Reagentes para diagnóstico de doenças infecciosas: Tendências de mercado e tecnologias diagnósticas-Uma análise comparativa. Nota Técnica do Projeto Vice-Presidência de Produção e Inovação em Saúde, FIOCRUZ, Mimeo.

[21] MCTI (2012) Ministério da Ciência, Tecnologia e Inovação. Sistema Integrado de Administração Financeira do Governo Federal.

http://www.mct.gov.br/index.php/content/view/5709.html

[22] BrazilianHealthDevice (2013) Dados do mercado. http://brazilianhealthdevices.com.br/market

[23] Leão, R., Oliveira, E. and Albornoz, L. (2008) Estudo setorial-Setor de equipamentos e materiais de uso em saúde. Secretaria de Ciência, Tecnologia e Insumos Estratégicos, Departamento de Economia da Saúde, Coordenação Geral de Economia da Saúde, Brasília.

[24] Gutierrez, R.M.V. and Alexandre, P.V.M. (2004) Complexo industrial da saúde: uma introdução ao setor de insumos e equipamentos de uso médico. BNDES Setorial, Rio de Janeiro, 119-155.

[25] ABIMO (2013) Dados econômicos. http://www.abimo.org.br/modules/content/content.php?pa ge=dados-economicos

[26] Shortell, S.M., Gillies, R.R. and Devers, K.J. (1995) Reinventing the American hospital. Milbank Quarterly, 73, 131-160. http://dx.doi.org/10.2307/3350254

[27] Mendes, E.V. (2001) Grandes Desafios do SUS. Instituto de Saúde Coletiva/UFBA. Casa da Qualidade, Tomos I e II, Salvador.

[28] Gadelha, C.A.G., Maldonado, J., Vargas, M., Barbosa, P.R. and Costa, L.S. (2012) A dinâmica do Sistema Produtivo da Saúde: Inovação e complexo econômico-industrial. Editora Fiocruz, Rio de Janeiro, 221 p.

[29] ANS (2013) Dados Gerais. http://www.ans.gov.br/materiais-para-pesquisas/perfil-dosetor/dados-gerais

[30] WHO (2012) World Health Organization. Europe HFA, Database. http://www.euro.who.int/hfadb

[31] Mckee, M. and Healy, J. (2000) The role of the hospital in a changing environment. Bulletin of the World Health Organization, 78, 803-810.

[32] Ministério da Saúde (2007) Programa Mais Saúde: Direito de todos-2008-2011 (PAC Saúde). Editora do Ministério da Saúde, Brasília.

http://bvsms.saude.gov.br/bvs/pacsaude/programa.php

[33] IBGE (2010) Instituto Brasileiro de Geografia e Estatística. PINTEC-Pesquisa Industrial de Inovação Tecnológica 2008, Rio de Janeiro.

[34] MDIC (2003) Ministério do Desenvolvimento, Indústria e Comércio Exterior. Política Industrial, Tecnológica e de Comércio Exterior. http://www.camara-e.net/_upload/20031126Diretrizes.pdf

[35] BRASIL (2007) Ministério da Ciência e Tecnologia e Inovação. Ciência, Tecnologia e Inovação para o Desenvolvimento Nacional: Plano de ação 2007-2010. (PAC da Inovação). Ministério da Ciência e Tecnologia e Inovação, Brasília. www.mct.gov.br

[36] MDIC (2008) Ministério do desenvolvimento, indústria e comércio exterior (2008). Política de Desenvolvimento Produtivo (PDP).

http://www.desenvolvimento.gov.br/pdp/arquivos/destswf 1224095287.ppt.

[37] Brasil (2011) Plano Brasil Maior 2011/2014 Inovar para competir. Competir para crescer.

http://www.brasilmaior.mdic.gov.br/publicacao/recursos/a rquivos/biblioteca/Apresentacao PBM - port rev abril 2012.pdf

[38] MS (2012) MINISTÉRIO DA SAÚDE. Informações fornecidas pela Secretaria de Ciência. Tecnologia e Insumos Estratégicos do Ministério da Saúde, em fevereiro de 2012.

[39] Pieroni, J.P., Reis, C. and Souza, J.O.B. (2010) A indús0 tria de equipamentos e materiais médicos, hospitalares e odontológicos: Uma proposta de atuação do BNDES. Complexo Industrial da Saúde, BNDES Setorial 31, 185226.

[40] Edquist, C., Hommen, L. and Tsipouri, L. (2000) Public technology procurement and innovation. Kluwer Academic Publishers, Boston, Dordrecht, London.

[41] Schmidt, F.H. and Assis, L.R.S. (2011) O Estado como cliente: Características das firmas industriais fornecedoras do governo. $17^{\mathrm{a}}$ edição do boletim Radar: Tecnologia, produção e comércio exterior. Instituto de Pesquisa Econômica Aplicada, Diretoria de Estudos e Políticas Setoriais, de Inovação, Regulação e Infraestrutura, Brasília.

[42] Rothwell, R. (1984) Technology-based small firms and regional innovation potential: the role of public procurement. Journal of Public Policy, 4, 307-332. http://dx.doi.org/10.1017/S0143814X00002774 